\title{
Methotrexate restores effector T cell responsiveness in juvenile idiopathic arthritis
}

\author{
Maja Bulatović, Sebastiaan Vastert, Frederik Verweij, Nico Wulffraat, Femke van Wijk, Berent Prakken \\ From 18th Pediatric Rheumatology European Society (PReS) Congress \\ Bruges, Belgium. 14-18 September 2011
}

\section{Background}

In juvenile idiopathic arthritis (JIA) the balance between immune activation and regulation is disturbed. Methotrexate (MTX) is a commonly used drug to induce disease remission in JIA patients, but the exact mechanisms of action remains unknown.

\section{Aim}

We hypothesized that MTX induces remission by restoring the balance between effector (Teff) and regulatory $\mathrm{T}$ cells (Tregs). Therefore we examined the effects of MTX on Teff/Treg activation and function in JIA patients.

\section{Methods}

Peripheral blood mononuclear cells (PBMCs) of 25 JIA patients were isolated prior to the start of MTX (T0) and 3 (T3) and 6 (T6) months after MTX start. Frequency and phenotype of FoxP3+ Tregs were analyzed ex vivo by flow cytometry and their suppressive function in CFSE suppression assays. Proliferation of CD4+ and CD8+ Teffs was determined with CFSE upon a 4-day culture in the presence of anti-CD3. Teffs cytokine production was measured ex vivo by flow cytometry upon PMA/ionomycin stimulation and in culture supernatants with luminex.

\section{Results}

MTX does not induce changes in frequency, phenotype or suppressive capacity in Tregs at all time points. However, Teffs show significantly increased proliferation at T6 (mean: $76.2 \%$ of CD4+ T cells, SD 18.3\%) than at T3 $(39.8 \%, 18.7 \%)$ and T0 $(49.0 \%, 21.1 \%) \quad(\mathrm{p}<0.01)$.

\footnotetext{
* Correspondence: m.bulatovic@umcutrecht.nl Department of Pediatric Immunology, University Medical Centre Utrecht, Wilhelmina Children's Hospital, Netherlands
}

Moreover, Teff proliferation at T6 is similar to healthy controls. Cytokine production (IL-10, IL-13, IL-17, IFN $\gamma$, $\mathrm{TNF} \alpha$ ) in supernatants was also increased at T6 compared to T3 and T0.

\section{Conclusion}

In contrast to our hypothesis, we observed no effects of MTX on Treg. Surprisingly, clinical improvement in JIA patients treated with MTX was associated with increased proliferation and responsiveness of Teffs. This suggests clear modulatory effects of MTX on Teffs rather than immunosuppression.

Published: 14 September 2011

doi:10.1186/1546-0096-9-S1-P131

Cite this article as: Bulatović et al:: Methotrexate restores effector T cell responsiveness in juvenile idiopathic arthritis. Pediatric Rheumatology 2011 9(Suppl 1):P131.
Submit your next manuscript to BioMed Central and take full advantage of:

- Convenient online submission

- Thorough peer review

- No space constraints or color figure charges

- Immediate publication on acceptance

- Inclusion in PubMed, CAS, Scopus and Google Scholar

- Research which is freely available for redistribution

Submit your manuscript at www.biomedcentral.com/submit

\section{() Biomed Central}

\section{Biomed Central}

